\title{
What is Distributed Morphology? *
}

\author{
Isah Abdullahi Muhammad ** \\ (Usmanu Danfodiyo University, Nigeria)
}

\begin{abstract}
Asking such a question in this theory is rare, because to cover the whole skeleton of this question with substantial flesh is not a simple deal. But yet the paper attempts this question indirectly by discussing such central issues: (a) "grammar" in Distributed Morphology, (b) "morphology" in Distributed Morphology, (c) what is Distributed Morphology? (d) what has been Distributed? (e) why Distributed Morphology? (f) post-syntactic operations in Distributed Morphology, (g) key features of Distributed Morphology, (h) current issues of debate in Distributed Morphology, (i) analysis of some words from Hausa in Distributed Morphology. Discussion and explanation of the above mentioned issues will give clear picture of Distributed Morphology theory.
\end{abstract}

Keywords: grammar, morphology, Distributed Morphology

\section{Introduction}

Since 1970, "morphology" has become a crucial topic of discussion in generative grammar, and to date, in the generative frame work we have two well-developed approaches, namely, lexicalism and non-lexicalism. The former approaches "lexicon" as an independent generative compound of word formation different from syntax. So, in this approach, there are two generative components "lexicon" and "syntax". But the latter type, repudiated the idea of traditional lexicon and the unity of word formation component, and regards "syntax" as the only one authentic generative engine of computation. Nonlexicalism approach here is Distributed Morphology. It was initiated and developed in Halle (1990), Halle \& Marantz (1993, 1994), Halle (1997) and Harley \& Noyer (2003). The question which this paper asks is "What is Distributed Morphology?"

However, from this paper's point of view, the content that will help to understand Distributed Morphology includes the following issues: "grammar" in Distributed Morphology, "morphology" in Distributed Morphology and then what is Distributed

\footnotetext{
${ }^{*}$ I thank Suleman Ibrahim Gatawa of Modern European Languages and Linguistics Usmanu Danfodiyo University, Sokoto, for making grammatical corrections and sincerely.

** Dr. Isah Abdullahi Muhammad: Department of Nigerian Languages, Faculty of Arts and Islamic Studies, Usmanu Danfodiyo University, Sokoto, Nigeria. P.M.B. 2346. Email: amisah2007@ yahoo.com.
} 


\section{Isah Abdullahi Muhammad}

Morphology? What has been Distributed? Why Distributed Morphology? What are post-syntactic operations? What are the key features of Distributed Morphology? What are the current debates in Distributed Morphology, as well as analysis of some words from Hausa language in Distributed Morphology. A reasonable explanation of these key issues will give a clear picture of Distributed Morphology theory.

\section{Grammar in Distributed Morphology}

The term "Grammar" is a very important aspect in the study of human language. Ndimele (2001:105) says: "We shall define grammar as a body of innate linguistic rules concerning a language which is passed by a normal speaker of that language."

Probably, because of the width of its meaning, Crystal (2007:217) stated that grammar is a central term in linguistics, but one which covers wide range of phenomena.

In related attempt, Scalise \& Fabrigas (2012:4) defined grammar as follows: Grammar is concerned as computational system that contains units and associates those structures with sounds and with meaning. This gives us three basic components of linguistic analysis:

(a) A computational system that combines simple units into bigger units (Syntax).

(b) A system that relates those units to physical signals (Phonology).

(c) A system that relates those units to meanings (Semantics).

But in Distributed Morphology, "syntax" is regarded as basic and prominent component of grammar, while Phonology and semantics spell-out the input of the syntactic structures. That is why in Distributed Morphology the minimalist "Y Model" was adopted as follows:

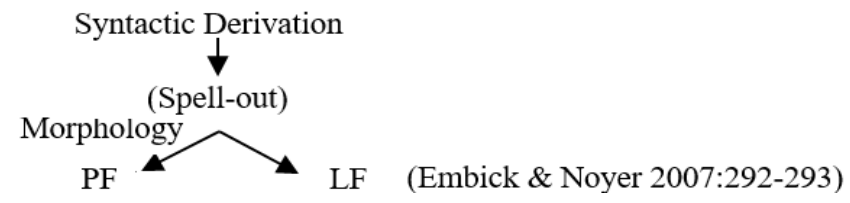

Figure 1. Y Model grammar structure

In explaining this figure, Embick \& Noyer (2007:292) stated that, from the programmatic minimalist perspective, the grammar must contain (a) a set of primitives, (b) a derivation system for combining these primitives into (a discrete infinity of) complex objects, (c) an interface with the conceptual/intentional system (LF) and (d) an interface with the articulatory/perceptual system (PF).

In the above exposition, traditionally, "a set of primitives" contain either completed words or lexical items which are complex containing phonological, syntactical and semantic properties and this is clear contravention of the principles and practice of Distributed Morphology. So, the syntactic derivation that appeared on the top of the grammatical chart contains only "abstract morphemes" devoid of any phonological 
property which in other words, is called "narrow lexicon". Also, numerated abstract morphemes are to be transferred to "spell-out" for the phonetic form interpretation and the logical form interpretation to form small phases and larger phases of the language. According to Noyer (2006:734), grammar is divided into the following three categories:

(a) Repositories containing listed information.

(b) Syntax proper.

(c) Post-syntactic mechanisms.

\section{3. "Morphology" in Distributed Morphology}

In the current trend of morphological research, the definition of "morphology" can either be on the assumption of its being morpheme-based or word-based. Nida (1949:1) asserts that morphology is the study of morphemes and their arrangement in forming words.

This definition is the example of morpheme-based assumption. In other words, Matthews (1991:9) says: "morphology is briefly the branch of grammar that deals with the internal structure of words." This also is the example of word-based assumption.

However, in Distributed Morphology, the story is different because "...syntax and morphology are names for the same thing" (Harley, 2010:35). Therefore, the definition and concept of morphology in Distributed Morphology can be as follows according to Embick \& Noyer (2001:558): "We use morphology here as a cover term for a series of operations that occur on PF branch following the point at which the syntactic derivation splits between PF and LF."

This shows that "morphology" in Distributed Morphology theory deals with syntax proper and post-syntactic operations such as lowering, linearization, dissociated morphemes, impoverishment, fission, fusion, vocabulary insertion, readjustment rules, etc. (Harley, 2013).

\section{What is Distributed Morphology}

Though, this is title of this paper but here, it will concentrate only on the definitions given by Distributed Morphology Scholars. According to Embick \& Marantz (2008:4), Distributed Morphology is a syntactic, piece based, realizational approach to morphology in which there are at least some 'late insertion' of phonological material into terminal nodes.

Harley (2010a:24) stated that Distributed Morphology is syntacticocentric, realizational, piece based, nonlexicalist theory of word (and sentence) formation.

Harley (2010b:4) also opines that Distributed Morphology is a morphosyntactic framework which employs the same combinatoric and interpretative mechanisms for both word formation and phrase formation. 
In a nutshell, Distributed Morphology is the study of proper syntactic and post-syntactic operations of words in a language.

\section{What has been distributed}

In regard to this question, according to Halle \& Marantz (1993:111-112), Distributed Morphology (here after D.M) aims to highlight the fact that the machinery of what traditionally has been called morphology is not concentrated in a single component of the grammar, but rather is distributed among several different components.

Harley \& Noyer (2003:463) also pointed out that the word "distributed" of Distributed Morphology refers to the separation of properties which in other theories are collected in lexicon.

Distributed Morphology distributes traditional "lexicon" into three lists:

(a) Morpheme lists: Contains abstract morphemes e.g. roots $(\sqrt{ })$, functional categorizers $\left.\left(<\mathrm{n}^{\mathrm{o}}, \mathrm{v}^{\mathrm{o}}, \mathrm{a}^{\mathrm{o}}\right\rangle\right){ }^{\mathbb{1}}$

(b) Vocabulary items: Contains lexical vocabulary item (Lvi) and functional vocabulary item (Fvi).

(c) Encyclopedia: This list contains both extra grammatical interpretations and idiomatic interpretations.

\section{Why Distributed Morphology}

In generative grammar from 1970s to 1980s, the morphological practices of that time are mostly "lexicalism". According to Guevara \& Scalise (2005:147), the term "lexicalism" refers to theoretical standpoint in generative linguistics according to which the processes that complex words (derivation and compounding) are accounted by a set of lexical rules, independent of and different from the syntactic rules of the grammar (i.e. word formation is performed by syntactic transformations).

So, in this assumption, morphology is totally a different entity, and the issue of "interface" is "morphology-syntax interface" denoting the relationship between different models of grammar.

But in the 1990s at MIT, the story began to change with the advent of "Distributed Morphology theory" which gave room and chance to those who think differently from "lexicalism". Even though, the idea started to emerge in Aronoff (1976) for shifting from strong lexicalism to weak lexicalism which assumes that the inflections are accounted for syntax. Sproat (1985) also claims the same thing, for reducing morphology entirely to

\footnotetext{
(1) $\sqrt{ }$ this stands for abstract a categorial root, while ' $<>$ ' stands for functional features, $\mathrm{n}^{0}$ nominalizer, $\mathrm{v}^{0}$ verbalizer, $\operatorname{adj}^{0}$ adjectivalizer.
} 
syntax. Halle \& Marantz (1993, 1994) initiated and developed "Distributed Morphology" which totally rejected the traditional lexicalism approaches (both strong and weak) to morphology and out-lined an elegant syntactic approach to word formation. Marantz (1997:202-203) spat fire on lexicalism by stating that "Lexicalism is dead, deceased, demised, no more, passed on... This failure is not generally known because no one listens to them to morphologists... But the people that work on word-sized domains are morphologists, and when morphologists talk, linguists nap".

$\mathrm{He}$ also went ahead and rejected the idea which considered the "word" domain of "special locus" of "special meaning" or "special sound structure process" or any "idiosyncratic" non compositional meaning. The main reason for promoting the idea of "Distributed Morphology theory" is in line with Embick \& Noyer's (2007:290) statement that the theory of Distributed Morphology proposes architecture of grammar in which a single generative system is responsible both for word structure and phrase structure. In particular, Distributed Morphology attempts to make precise claim that derivation is syntactic. According to this approach, syntactic approach serves as the skeleton on which all complex forms are based.

Also, among the reasons which this paper foresees for resorting to Distributed Morphology includes:

(a) Weakness of lexicalism approach to word formation.

(b) To give a true picture of syntax-morphology interface not morphology-syntax interface which is vague and unclear.

(c) To simplify and reduce the burden from two generative models to a single generative grammatical analysis. In regard to this point, Williams (2004:1) emphasized the position of Halle \& Noyer (1999) as follows: "Elements within syntax and within morphology enter into the same types of constituent structures (can be diagrammed through binary branching trees)."

\section{Post-syntactic operations in Distributed Morphology}

The post-syntactic operations of Distributed Morphology, which this paper is able to discuss included: fusion, fission, impoverishment, morphological merger, dissociated morphemes, linearization.

\subsection{Fusion}

According to Siddiqi (2006:42), fusion "is for cases where formal features from several different terminal nodes are realized by one vocabulary item". A good example of fusion is Hausa pronoun (or agreement element) where person, number, and gender feature (phi-features) are fused and exponed as a single vocabulary item ya ('he') or $t a$ ('she').

\subsection{Fission}


"Fission takes one position of exponence and splits into many" (ibid:43). This can be traced in Hausa plural formation as in the following examples:

turmii ('mortar'), turaamee ('mortars'); kurmaa ('dumb'), kuraame e ('dumbs')

In the above examples, we can see how plural feature was realized by splitting into two position of exponence in the middle and final of roots.

\subsection{Impoverishment}

According to Embick \& Noyer (2003:311), when impoverishment occurs, a feature of a morpheme is deleted in a specific context. The good example of "impoverishment" is deleting of "gender" feature in Hausa plural as the following examples:

yaaroo ('boy sing, masc'), yaaraa ('boys pl'); jaakii ('donkey sing, masc'), jaakunaa ('donkeys pl')

\subsection{Morphological merger}

Fabrigas (2005:28) asserts that morphological merger is the general operation that puts morphemes together to construct words in Distributed Morphology framework. In other words, Siddiqi (2006:42) mentioned that fundamentally, merger is the process whereby an abstract morpheme realized by an affix is attached to a stem.

The Hausa word gidaa ('house') is constructed with two vocabulary items. The root gidand suffix - $a a$ putting - $a a$ adjacent to root gid- will yield a complete word gidaa.

\subsection{Dissociated morpheme}

According to Embick \& Noyer (2007:309), we refer to material (features or terminal nodes) added in PF as "dissociated". Harley (2010:16) explained that insertion of new terminal nodes ("dissociated morphemes").

In the following examples of Hausa sentences, gidaa is masculine (masc.), singular (sing.), noun (n.). In a correct sentence what will come after gidaa must agree with these features of "masc." and "sing.", that is why we have nee next to word gidaa because of that agreement feature between gidaa and nee. It is the same case, in example (1b) where faraa is adjective, singular, feminine (fem.). So what will come after it must also share and agree with these features of "fem." and "sing." that is why we have cee next to the word faraa. Both of these non-auxiliary sentences will crash if we put copular cee next to gidaaa or put nee next to faraa, since it is ungrammatical because there is no agreement between cee and gidaa, just as there is also no agreement between nee and faraa. It just likes putting 'her' in place of 'him' or to put 'him' in place of 'her'.

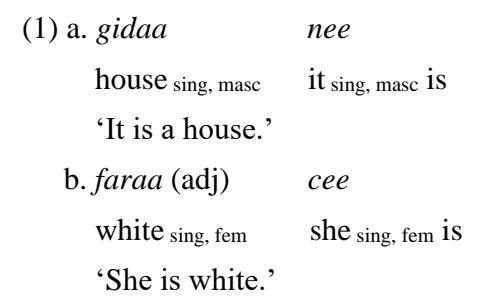


What is Distributed Morphology?

\subsection{Linearization}

According to Embick (2003:304), linearization is the representation of linear order in the $\mathrm{PF}$ component of the grammar, as revealed by case in which PF rules affix one element to another. This paper considers morphological merger as different mechanism from "linearization", though they are related, but the function of "morphological merger" is to merge two elements node into one. Linearization focuses on orderly concatenation of both M-word and sub-words.

The Hausa word tiilastaawaa ('compulsion') contains five exponents, which are put in order. Its structure can be represented as follows: $\sqrt{T I I L A S}+\mathrm{n}^{0}+\mathrm{v}^{0}+\mathrm{n}^{0}$. This means the root TIILAS was categorized as noun with $\varnothing$ (zero exponent) noun categorizer, followed by verbalizer $-\mathrm{v}^{0}(-t a a)$ and finally nominalizer $-\mathrm{n}^{0}(-w a a)$. If you can attempt to put any one of the vocabulary items in a wrong position such as tiilastaawaa to ${ }^{*}$ tiilaswaataa, the entire structure will crash and turn to an ungrammatically structured word in Hausa.

\section{Key features of Distributed Morphology}

Halle \& Marantz (1994) discussed some basic features which distinguished Distributed Morphology from other morphological theories. Williams (2004) and Embick (2015) added more related points to it. Halle \& Marantz (1994:275-277) explained what distinguishes Distributed Morphology from other approaches, and these features include: late insertion, under-specification, syntactic structure all way down.

(a) Late insertion: "The terminal nodes that are organized into familiar hierarchical structures by the principles and operations of the syntax proper are complexes of semantics and syntactic features but systematically lack all phonological features. The phonological features are supplied after the syntax by the insertion of vocabulary items into the terminal nodes. Vocabulary insertion (VI) adds phonological features to the terminal nodes, but does not add the semantic/syntactic features making up the terminal nodes."

(b) Under-specification: "In order for vocabulary item to be inserted in a terminal node, the identifying features of the vocabulary must be a subset of the features at the terminal node. Insertion may not take place if the item has identifying features that do not appear at the node. The item needs not match every feature specified in the node; rather vocabulary items are characteristically under-specified with respect to the features of the nodes into which they are inserted. It is therefore not uncommon for several vocabulary items to be available for insertion into a given node. The most highly specified vocabulary item whose identifying features are a subset of the features of the terminal node wins the competition and is inserted."

(c) Syntactic structure all way down: "The terminal nodes into which vocabulary items are inserted are organized into hierarchical structures determined by the principles and 
operations of the syntax."

Williams (2004:11-12) further supplied trio distinguishing features which includes piece-based, competition and impoverishment.

(a) Piece-based: Piece-based in Distributed Morphology, refers to the notion that the syntax takes morphemes as basic, rather than morphological process.

(b) Competition: Williams (2004:17) also stated that every grammatical model these days has some notion of competition; two forms vie for a certain role and on general grounds, one wins excluding the other from that role.

However, Embick (2015:21) added to following features of Distributed Morphology:

(a) Syntactic: The theory is non-lexicalists. There is no pre-syntactic lexicon in which words are derived or stored. The only generative component in grammar is syntax thus, words have no privileged architectural status.

(b) Morphemes: The approach is pieced based. The fundamental units of morphology are discrete pieces arranged in hierarchical structures called "morphemes".

(c) (Some) Late Insertion: For certain morphemes in the approach assumed here, at least the functional morphemes, phonological material is supplied only on the PF branch via the operation of vocabulary insertion.

(d) Full Decomposition: No complex objects are stored in memory; every complex object must be derived by the grammar, every time it is employed.

\section{Current issues of debate in Distributed Morphology}

The current issues of debate in Distributed Morphology which this paper discovered include:

(a) Approaches to "roots" in Distributed Morphology vary. Initially, "late insertion approach" was first assumption by proponents of Distributed Morphology. But later, "early insertion approach" was also promoted in Embick (2000, 2015). So, in conclusion, there are two approaches to roots in Distributed Morphology theory.

(b) Distributed Morphology is "piece-based" from its inception to date, but Embick \& Halle (2005) used "readjustment rules" to clear some facets of their argument. So, the question is do we need to accommodate readjustment rules analysis which is "non-piece-based" as an addition to piece-based in Distributed Morphology? Though, Siddiqi (2006:63) stated his position that readjustment rules are no longer necessary in this model of the grammar.

(c) In case of vocabulary insertion, initially, roots are inserted based on free and choice, while functional vocabulary items are based on competition. But this was challenged by De Belder (2011) and De Belder \& Craenbroeck (2014) on the basis that both are inserted based on competition. 


\section{What is Distributed Morphology?}

(d) Categorizers, according to Marantz (2001), are functional heads, but to Panagiotidis (2011) categorizers are "lexical heads".

(e) The issue of "blocking" in Distributed Morphology. In Embick \& Marantz (2008), there is no blocking between word level and the above word level, but to Hankamer \& Mikkelsen (2013:19), there is indeed "blocking" above word level.

\section{Analyses of some Hausa words in Distributed Morphology}

The following Hausa words can be used for the analysis:

huulaa (n. 'cap'), faraa (adj. 'white'), kaamaa (v. 'to catch'), tsaye (adv. 'standing')

Since Distributed Morphology is a syntactic approach to word formation, in fact, it has brought syntax down inside words and morphemes. In this regard, Marantz (2007:193) provided such structure, generally for the word form from root and those form from word (Simplex or complex):

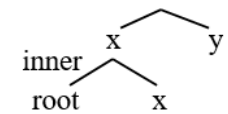

Figure 2. Complex word syntactic structure

Marvin (2002): also illustrated the following structure of words:<smiles>[Y][C][Te]</smiles>

Figure 3. Simple word syntactic structure

Embick (2012:79) added the following branching structure: $\sqrt{ }$ ROOT y] x].

Based on the aforementioned structures, the Hausa words can be analyzed as follows:

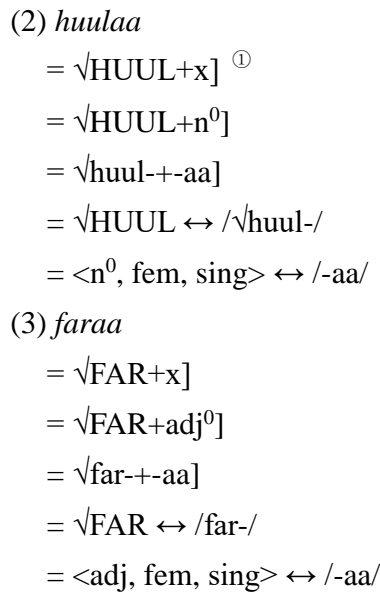

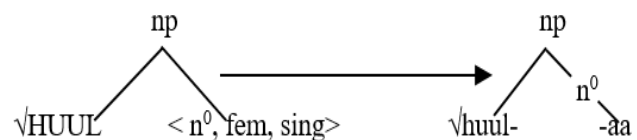

Figure 4. Syntactic structure of simple noun in Hausa

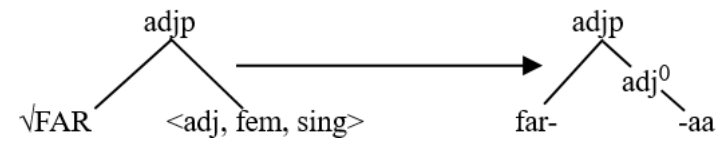

Figure 5. Syntactic structure of simple adjective in Hausa

\footnotetext{
(1) Always abstract root in Distributed Morphology is in capital letters with square symbol ' $\sqrt{ }$ '.
} 


\section{Isah Abdullahi Muhammad}

(4) kaamaa

$=\sqrt{\mathrm{KAAM}}+\mathrm{x}]$

$\left.=\sqrt{ } \mathrm{KAAM}+\mathrm{v}^{0}\right]$

$=\sqrt{ }$ kaam-+-aa

$=\sqrt{ }$ KAAM $\leftrightarrow /$ kaam $-/$

$=\mathrm{v}^{0} \leftrightarrow /-\mathrm{aa} /$

(5) tsaye

$=\sqrt{ } \mathrm{TSAY}+\mathrm{x}]$

$\left.=\sqrt{ } \mathrm{TSAY}^{\mathrm{ada}} \mathrm{v}^{0}\right]$

$=\sqrt{ }$ tsay-+-e]

$=\sqrt{ }$ TSAY $\leftrightarrow /$ tsay $-/$

$=\operatorname{adv}^{0} \leftrightarrow /-\mathrm{e} /$
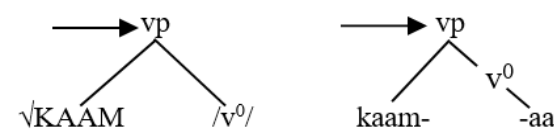

Figure 6. Syntactic structure of verb in Hausa

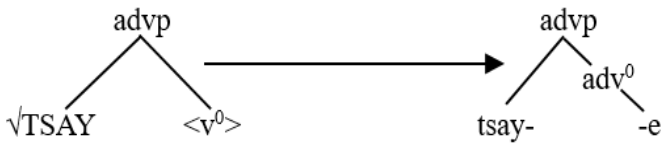

Figure 7. Syntactic structure of adverb in Hausa

\section{Conclusion}

To find a tentative answer to the question "what is Distributed Morphology?" is a very hard task. But this paper made an attempt, through these subtitles: (a) "grammar" in Distributed Morphology, (b) "morphology" in Distributed Morphology, (c) what is Distributed Morphology, (d) what has been distributed? (e) why Distributed Morphology? (f) post-syntactic operations in Distributed Morphology, (g) key features of Distributed Morphology, (h) current issues of debate in Distributed Morphology, (i) an analysis of some words from Hausa within Distributed Morphology.

This paper is a little contribution to the understanding of how Distributed Morphology works. And going deeper into the issues presented in the paper will assist to discover more exciting revelations about the theory.

\section{References}

Aronoff, M. 1976. Word Formation in Generative Grammar [M]. London: Massachusetts Institute of Technology.

Crystal, D. 2008. A Dictionary of Linguistics and Phonetics Sixth Edition [M]. United Kingdom: Blackwell Publishing.

De Belder, M. 2011. Roots and affixes: Eliminating Lexical Categories from Syntax [D]. Ph.D. Dissertation. Universiteit Utrecht, Netherlands.

De Belder, M. \& J. V. Craenenbroeck. 2011. How to Merge Root [Z]. MS

De Belder, M. \& J. V. Craenenbroeck. 2014. On Functional Vocabulary Items in Root Positions [Z]. MS.

Embick, D. 2000. Features, Syntax, and Categories in the Latin Perfect [J]. Linguistic Inquiry, 31(2):183-230.

Embick, D. \& R. Noyer. 2001. Movement Operations After Syntax [J]. Linguistic Inquiry, 32 (4): 555-595. Embick, D. \& A. Marantz. 2008. Architecture and Blocking [J]. Linguistics Inquiry, 38(1): 1-53.

Embick, D. 2003. Linearization and Local Dislocation: Derivational Mechanics and Interaction [J]. Linguistic Analysis, 33(3-4): 301-336.

Embick, D \& M. Halle. 2005. On the Status of Stems in Morphological Theory [A]. In T. Geerts \& H. 


\section{What is Distributed Morphology?}

Jacobs (eds.), Proceedings of Going Romance 2003 [C]. Amsterdam: John Benjamins Amsterdam/ Philadelphia, 58-59.

Embick, D. \& R. Noyer. 2007. Distributed Morphology and Syntax/Morphology Interface [A]. In G. Ramchand \& C. Reiss (eds.), Oxford Handbook of Linguistics Interface [C]. Oxford: Oxford University Press.

Embick, D. \& A. Marantz. 2008. Architecture and Blocking [J]. Linguistics Inquiry, 38(1): 1-53.

Embick, D. 2008. Variation and Morphosyntactic Theory: Competition Fractioned [J]. Language and Linguistic Analysis Compass, 2(1): 59-78.

Embick, D. 2010. Localism versus Globalism in Morphology and Phonology [M]. Cambridge: MIT Press.

Embick, D. 2012. Roots and Features (a categorial postscript) [J]. Theoretical Linguistics, 38(1-2): 73-89.

Embick, D. 2015. The Morpheme: A Theoretical Introduction [M]. Boston/ Berlin: de Gruyter.

Fabregas, A. \& S. Scalise. 2012. Morphology from Data to Theories [M]. Edinburgh: Edinburgh University Press.

Halle, M. 1990. An Approach to Morphology [A]. Proceedings of the North East Linguistics Society [C]. 20, Vol. 1. Amherst: GLSA University of Massachusetts, 150-184.

Halle, M. \& A. Marantz. 1993. Distributed Morphology and the Pieces of Inflection [A]. In K. Hale \& S. J. Keyser (eds), The View from Building 20: Essays in Linguistics in honor of Sylvain Bromberger [C]. Cambridge, MA: MIT Press.

Halle, M. \& A. Marantz. 1994. Some Key Features of Distributed Morphology [J]. MIT Working Papers in Linguistics, 21:275-288.

Halle, M. 1997. Distributed Morphology: Impoverishment and Fission [A]. In M. Halle, B. Bruening, Y. Kang \& M. McGinnis (eds.), PF: Papers at the interface MITWPL 30 [C], 423-449.

Hankamer, J. \& L. Mikkelsen. 2013. Structure, Architecture, and Blocking [OL]. Retrieved from linguistic berkely-edu.mikkelsen/papers.

Harley, H. \& R. Noyer. 2003. State-of-the Article: Distributed Morphology [A]. In L. L-S. Chang \& R. Sybesma (eds.), The Second Glot State-of-the-Article Book: The Latest in Linguistics [C]. Berlin: Mouton de Gruyter, 463-495.

Harley, H. Semantics in Distributed Morphology [OL]. Downloaded from www.Ling.auf.Net/Lingbuzz/ 001528/Current.Pdf.

Harley, H. 2010. The Syntax/Morphology Interface [OL]. Retrieved from: heidiharly.com/haeidiharley /WP-Cont.

Harley, H. 2013. Cycles, Vocabulary Items and Stem forms in Hiaki [A]. In O. Matushansky \& A. Marantz (eds.), Distributed Morphology Today [C]. Cambridge, MA: MIT Press, 117-134.

Marvin, T. 2002. Topics in Stress and Syntax of Words [D]. Ph.D. Dissertation. MIT.

Matthews, P. H. 1991. Morphology [M]. London: Cambridge University Press.

Marantz, A. 2000. Words and Things [Z]. Handout. MIT.

Marantz, A. 2007. Phases and Words [A]. In S-H. Choe (eds.), Phases in the theory of grammar [C]. Seoul: Dong In., 191-222.

Marvin, T. 2002. Topics in Stress and Syntax of Words [D]. Ph.D. dissertation. MIT.

Nida. E. A. 1949. Morphology: The Descriptive Analysis of Words [M]. USA: University of Michigan Press.

Ndimele, O. (ed.). 2001. Readings on Language [M]. Port Harcourt: M\&J Orbit Communications Ltd.

Noyer, R. 2006. Distributed Morphology [A]. In K. Brown (ed), Encyclopedia of Language \& Linguistics, Second Edition [C]. Vol. 3. Oxford: Elsevier, 734-737.

Panagiotidis, E. P. 2011. Categorial Features and Categorizers [J]. The Linguistic Review, 28: 365-386.

Panagiotidis, E. P. 2014. A Minimalist Approach to Roots [A]. In P. Kosta, S. L. Franks, T. Redeva-Bork \& L. Schurcks (eds.), The Contribution from Minimalism and Beyond. Radicalizing the Interfaces [C]. Amsterdam: John Benjamins Publishing Company, 287-303.

Siddiqi, D. 2006. Minimize Exponence: Economy Effects on A Model of the Morphosyntactic Component of The Grammar [D]. Ph.D. Dissertation. Department of Linguistics, University of Arizona.

Siddiqi, D. 2009. Syntax Within Word: Economy, Allomorphy, and argument selection in Distributed Morphology [M]. Amsterdam: Benjamins Publishing Company. 


\section{Isah Abdullahi Muhammad}

Sproat, R. 1985. On Deriving the Lexicon [D]. Ph.D. Dissertation. MIT.

Williams, E. 2004. Dumping Lexicalism [A]. To appear in G. Ramchard \& C. Reiss (Eds.), Oxford Handbook of Linguistic Interfaces [C]. Oxford: Oxford University Press, 1-55. 